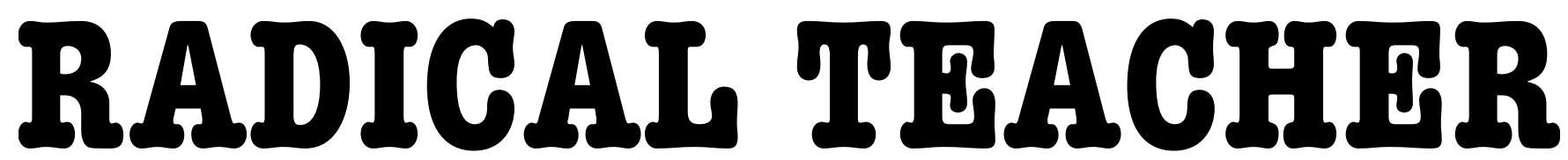

A SOCIALIST, FEMINIST, AND ANTI-RACIST JOURNAL ON THE THEORY AND PRACTICE OF TEACHING

\title{
Brief Introductions: \\ Gender, Visual Culture, and the Carceral State
}

by Erica Rand

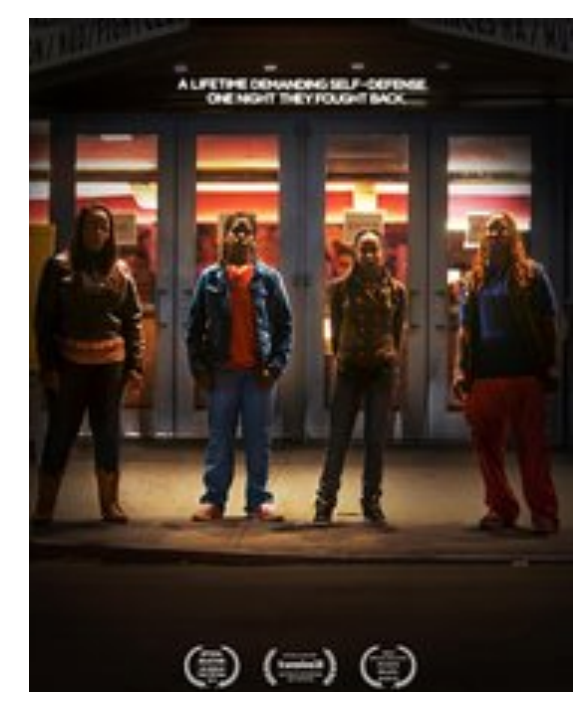

OUT IN THE NIGHT, BLAIR DAROSH-WALTHER'S 2014 DOCUMENTARY ABOUT THE NEW JERSEY 4, A GROUP OF

YOUNG BLACK LESBIAN FRIENDS, SOME GENDER NONCONFORMING, WHO WERE UNJUSTLY INCARCERATED AFTER ACTING IN SELF-DEFENSE AGAINST A HARASSER. 
I n the Winter semester of 2016, I switched up the beginning of Gender and Visual Culture, a 200level course I teach regularly at Bates College, to take advantage of a one-time opportunity: extensive programming for Martin Luther King, Jr. Day on "Mass Incarceration and Black Citizenship." Since the mid-1990s, Bates, an expensive liberal arts college in Lewiston, Maine, has recognized the day with workshops, talks, films, performances, a debate, volunteer opportunities, a keynote, and other activities organized around a theme and developed by a committee of faculty, staff and students over the course of a year. This practice stems partly from campus activism. After the federal holiday began in 1986 came years of protest that Bates would not honor it. Many of us refused to teach that day. Meanwhile, on three different occasions between 1989 and 1994, faculty canceled classes for teach-ins: after the harassment of a female faculty member; after George H.W. Bush declared the official start of what is now called the "first Gulf War"; and after racist, anti-Semitic, and anti-queer graffiti generated stupendous student activism (also involved in forcing the other days) to have a day dedicated to coalition organizing. Suspending classes annually on MLK, Jr. Day for programming had the excellent purpose of regularizing the social-justice teach-in day-although ask yourself who benefits from such days being less disruptive to business-as-usual when you can plan for them in advance-and, fundamentally, of declaring the central importance of anti-racist, multi-issue activism and education in a majority white institution in the statistically whitest state in the nation.

I want to indicate for the record, however, since our official PR unsurprisingly omits it, that upper administration supported installing the teach-in model partly because it conveniently allowed the institution to recognize the day without giving hourly and salaried staff paid time off. Thus while Bates sometimes uses the "a day on, not a day off" associated with the designation of Martin Luther King, Jr. Day, since 1994, as a Day of Service, that usage camouflages its equal aptness to describe a labor issue for people whose "day on" and not "off" is mandatory and sometimes little altered by the day's events, although staff are supposed to have some leeway to participate. (None of this is surprising for an institution that, several years later, used dubious and duplicitous tactics ill-befitting its selfpromotion as egalitarian to squash dining-service workers' attempts to unionize.)

In any case, while I always require students to participate in MLK, Jr. Day activities-not least because white students often skip it for skiing without a gradelinked assignment-I don't always alter my course design significantly for the theme. This year I did. The racist, gender-policing violence of the carceral state, which often depends on visual scrutiny, is integral to the context and content of the course. Yet I faced a challenge because MLK, Jr. Day occurred only a week after the term started. Since the course, cross-listed in Art and Visual Culture and in Women and Gender Studies, serves as an introduction to visual studies and/or gender studies for many of the firstyear through senior students taking it, I had to figure out how to introduce those large subject areas and the prison industrial complex in two class sessions that also required time-consuming activities like going over the syllabus.

To do so, I assigned Eric Stanley's essay "Fugitive Flesh: Gender Self-Determination, Queer Abolition, and Trans Resistance" to accompany our discussion of beginning gender concepts. An introduction to the anthology Captive Genders: Trans Embodiment and the Prison Industrial Complex, the text, besides being keyed to the MLK, Jr. topic, appealed to me for the way that Stanley interrupts some prevalent tendencies, especially for my traditionally college-aged, often privileged students, to individualism and self-discovery. For example, Stanley

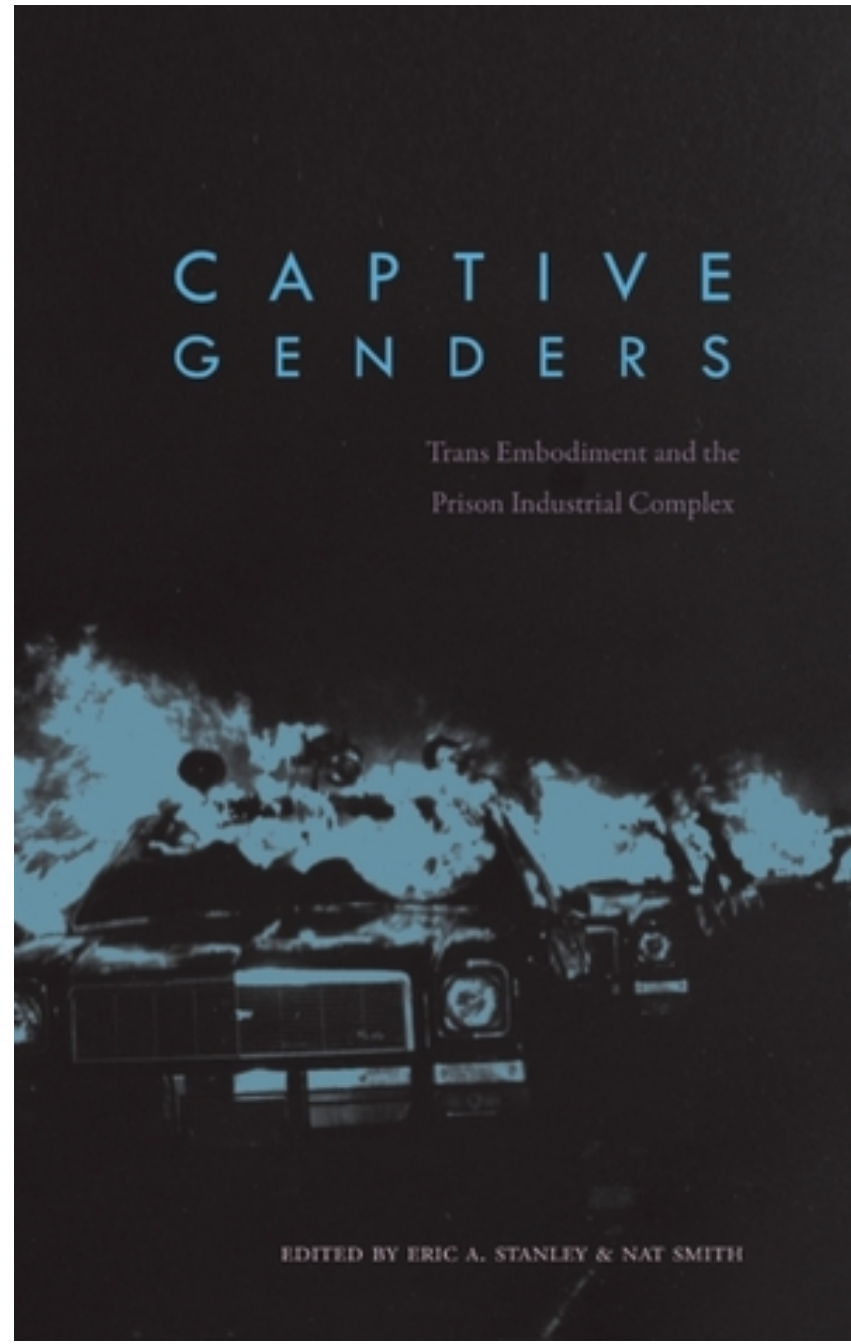

defines gender self-determination, not as a personal goal, but as a collective project to "create the most space for people to express whatever genders they choose at any given moment" and insists that gender identities, not simply sprung from within, are always formed in relation to power (p. 11).

I also assigned several other pieces. They included a recent New York Times video and text piece about Kricket Nimmons, one of the first trans people to undergo surgical transition procedures partly funded through Medicaid. Nimmons described, among other aspects of her history, the role of her gender identity in life circumstances that 
contributed to a period of incarceration. We also discussed a recent blog post by black artist and art professor Steve Locke called "I Fit the Description . . .," about being stopped by police as a potential burglary suspect on his way to his professor job, and looked at Locke's artwork, particularly Spectators (2003-4 and ongoing). For the series, Locke made postcards from lynching images, on display in a widely attended exhibit when he began the project, from which he had digitally deleted the victims to "remove the spectacle of flaming, twisted, and charred black bodies and center the focus on the real horror of the activity-the murderers' confidence in their actions." His experience and artwork show how habits of looking figure in the stigmatization and criminalization of people seen to depart from racialized ideals of masculinity, femininity, and heteronormativity.

I was happy with the immediate results of this early curriculum. The class discussions before and after MLK, Jr. Day seemed to go well, as did the short writing assignment linked to it. As I told the students, I'd opted to throw a lot out there at an accelerated pace. It was more than fine to be confused if the topics were new, and even if they weren't. By the end of the second week, I'd also rocked the complacencies of a few gender-studies majors with Julia Serano's challenge in her spoken word performance Cocky to the notion that genitals have intrinsic gender (since some women have penises, for example, penises are not male and people who have them are not "male bodied") and in the argument in her short essay "Performance Piece" that gender, contrary to a popular gender studies truism, is not always most importantly "a performance." More than hoping for mastery, I sought evidence that the material, if confusing, had been question-generating, assumption-confounding confusing, rather than throw-upyour-hands-and-walk-away confusing. I found it.

I was still pretty satisfied at the halfway point. To revisit our early focus on mass incarceration, I showed Out in the Night, blair darosh-walther's 2014 documentary about the New Jersey 4, a group of young black lesbian friends, some gender nonconforming, who were unjustly incarcerated after acting in self-defense against a harasser. Students were well prepared to discuss the role of the visual in the interconnected workings of gender appraisal, surveillance, self-fashioning, pleasure, policing, and violence as well as the politics of authority in relation to the director's statement on the film's website about making the documentary as a white woman.

By the end of the semester, however, I had recognized a continuing problem that a student's question regarding the final paper helped me see the extent of. The paper required students to use course materials, among possibly other sources, to evaluate a group project that asked students to make, design, or curate visual material about gender in the complexity we had discussed. The student, who had been doing engaged, very good work in the class, wrote to me that because, as she perceived it, the majority of readings concerned transgender narratives, and her group project didn't address trans issues, she was having trouble finding relevant sources to bring to her assessment.
I should have done more, early and often, to situate this material and our work with sources in relation to one of the learning objectives listed on the syllabus, that students will be able to "situate trans and queer gender at the centers rather than the margins of gender studies." While that objective was definitely accomplished in the sense of central meaning important-even leading some students, like the one I just mentioned, to magnify the quantity of "transgender narratives"-students did not always recognize, despite my prodding, that the work people produce as and about trans and/or gendernonconforming subjects bears on gender more broadly. They missed that point sometimes even when materials explicitly addressed gender in general or made that very point explicitly. And the effects of missing it can be enormous. As Dean Spade emphasizes repeatedly, including in a short reading I assigned called "Dress to Kill, Fight to Win," they can include heightened stigmatization and gender policing of people whose practices, such as body modification, are then misconstrued as marginal. The effects also include the failure to recognize trans and/or gender non-conforming people in the fullness of their roles as makers, critics, and theorists.

Next time I teach the course, I think I'm going to stick with Stanley's essay and related material for gender introduction. The context of mass incarceration remains regardless of the programming that generated my switchup. But I clearly have a lot of work to do.

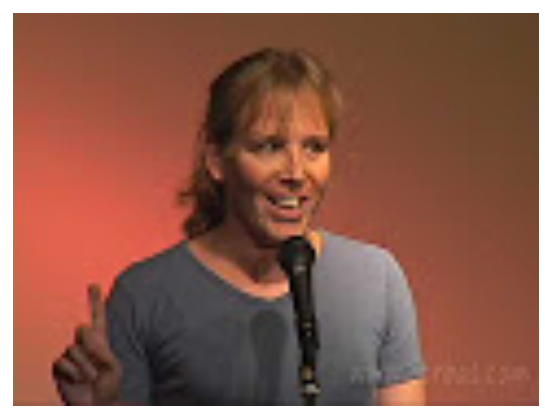

JULIA SERANO IN "COCKY," WRITTEN AND RECORDED IN 2003 AT THE BERKELEY POETRY SLAM 


\section{References}

Bracken, Kassie and Andrew Blackwell, "Becoming Kricket," Video, New York Times, 2015.

dorosh-walther, blair. Out in the Night Director's Statement. http://www.outinthenight.com/wpcontent/uploads/2015/05/OUTINTHENIGHT_PressKit_May20152.p df.

Locke, Steve., "I Fit the Description. . . ," Art and Everything After: Steve Locke's Blog About Art and Other Stuff (blog), December 5 , 2015 (http://artandeverythingafter.com/i- fit-the-description/).

Locke, Steve. Spectators (2003-2004).

http://www.stevelocke.com/Source/spectator.html).

Out In The Night. Directed by blair dorosh-walther. The Fire this Time Film, 2014.

Serano, Julia "Performance Piece." In Gender Outlaws: The Next Generation, edited by Kate Bornstein and S. Bear Bergman, 8588. Berkeley: Seal Press, 2010.

Serano, Julia, "Cocky." Written and recorded in 2003 at the Berkeley Poetry Slam. Published April 27, 2016. Text in Draw Blood. Oakland, CA: Hot Tranny Action Press, 2004 Forthcoming in Outspoken: A Decade of Transgender Activism \& Trans Feminism. Switch Hitter Press, 2016.

Sontag, Deborah, "'A Whole New Being': How Kricket Nimmons Seized the Transgender Moment," New York Times, December 12, 2015

Stanley, Eric. "Fugitive Flesh: Gender Self-Determination, Quee Abolition, and Trans Resistance." In Captive Genders: Trans Embodiment and the Prison Industrial Complex, edited by Stanley and Nat Smith, $2^{\text {nd }}$ ed., AK Press, 2015

Spade, Dean. "Dress To Kill, Fight to Win," 2003. Published in LTTR, 2007, http://www.lttr.org/journal/1/dress-to-kill-fight-to-

\section{Call for Teaching Notes for Radical Teacher}

Is there a book, film, essay, poem, or story that you've found particularly useful in the classroom and want to share with other Radical Teacher readers? We are especially interested in Teaching Notes on new materials not widely known, but we would also like to hear about newly rediscovered older works, as well as new ways of teaching familiar ones.

Or has something challenging, encouraging, or frustrating happened in class? If you think our readers can learn from your experience-whether you handled things well, handled them badly, or are still trying to decide-we'd like to hear about it.

Contributions should run about 500 to 1,500 words. If you'd like to see some sample Teaching Notes, check out "Recent Issues" on our web site.

Please send your Note to Bob Rosen at RosenR@wpunj.edu with the header "Teaching Note" and also submit it online at http://radicalteacher.library. pitt.edu/. 